\title{
Duty hours vs professional ethics ACGME rules create conflicts
}

\author{
Dan Larriviere, MD, JD
}

I n July 2003, the new duty hour requirements promulgated by the Accreditation Council for Graduate Medical Education (ACGME) went into effect. Broadly stated, the rules limit residents to 80 hours a week and no more than 24 hours on call at a time. They provide a 6 -hour window for transfer of patient care and didactic activities for residents who are postcall. In addition, residents must not take call more than every three days and must have one day in seven free from patient-care responsibilities.

The purpose of the rules is to improve patient safety by ensuring that residents will be well-rested and less likely to make mistakes when taking care of patients. The impetus for change is the increase in the severity of illness in patients admitted to the hospital, the increased public attention to the issue of medical errors in general, and the subsequent threat of federal legislation. ${ }^{1}$ In addition, the ACGME points to sleep studies that link sleep deprivation to declines in cognitive functioning as another reason for implementing the new rules. ${ }^{1}$

The relative strengths and weaknesses of the rules in improving patient outcomes are debated in other essays. ${ }^{2}$ My purpose here is to evaluate the new rules in light of their possible effect on ethically acceptable behavior of residents. I will argue that the new rules make it more difficult to practice ethically sound medicine and may actually serve to discourage such behavior.

The Ethics and Humanities Subcommittee of the Practice Committee of the American Academy of Neurology (now the Ethics, Law \& Humanities Committee) developed a Code of Professional Conduct to formalize the standards of professional behavior for "neurologist members of the Academy" that makes no distinction on its face between residents and physicians who have completed their training. Several provisions are applicable to the issue at hand:

\section{2: Fiduciary and contractual basis}

The neurologist has fiduciary and contractual duties to patients. As a fiduciary, the neurologist has an ethical duty to consider the interests of the patients first. [Emphasis added.]

5.1: The patient's interest is paramount

Whenever a conflict of interest arises, the neurologist must attempt to resolve it in the best interest of the patient. If the conflict cannot be eliminated, the neurologist should withdraw from the care of the patient.

\section{4: Health care institutional conflicts}

The neurologist generally should support the patient's medical interests when they are compromised by policies of the health care institution or agency.
As the Code makes clear, whenever the interests of the patient and those of the physician or the physician's institution conflict, the patient's interests are paramount. If a physician fails to adhere to these guidelines, he or she is subject to disciplinary action.

By enunciating a standard of behavior and providing a deterrent for actions that are inconsistent with such a standard, the Academy has created a fairly conventional tool for behavior modification, to the extent that it is needed.

However, under the new system promulgated by the ACGME, this paradigm is turned upside down. Residents who work beyond the hour limits because of perceived ethical obligations to do so are $a$ priori in violation of the ACGME guidelines and must prove that they were ethically obligated to violate them or put their program at risk of losing its accreditation. Instead of forcing people to answer for unethical behavior, we will be making them justify ethically sound practices.

This assumes that the ACGME will accept ethical justifications for hour violations. As of this writing, no formal mechanism is in place that would allow programs to show that hour violations are a result of ethically-mandated behavior (although a "hotline" is in place to report violations). It is unclear whether or not this omission is merely an oversight or whether it is the position of the ACGME that

From the Department of Neurology, University of Virginia, Charlottesville, VA; and Johns Hopkins University, Baltimore, MD.

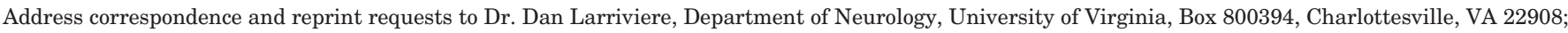
e-mail: dgl6t@virginia.edu 
there are no situations that could arise that would create a conflict between the ethical duty of a resident to remain with her patient and the duty hour requirements.

Let us assume that there are situations in which the hour requirements will conflict with an ethical duty as perceived by the resident and that the ACGME will recognize such situations as justifications for a violation of the hour requirements. Presumably, residents and residency programs will have to provide the ACGME with the facts surrounding the resident's decision to remain in house. What happens next is unclear. Will the ACGME, the program in question, or the resident be the final arbiter of what does or does not constitute ethical behavior? Taking it a step further, how will residents who are put in such a position react? Will they remain in the hospital, confident that their perception of ethically mandated behavior will be accepted as a legitimate reason for violating the rules? Or will they hand over their responsibilities to the on-call resident despite their beliefs to the contrary, because it is time to do so and by doing so they avoid jeopardizing their program should the opinion of the ACGME usurp their own? Maybe they will do neither. Perhaps they will simply lie about the hours they were in the hospital in order to avoid the risk to their program as well as the opprobrium of the ACGME.

The conflict highlights the problem of trying to define the duties and responsibilities of a physician solely by time. Our duty to our patients does not end simply because a timer has gone off. Our duty ends when the patient's condition is such that it is safe for us to hand over care to another. To hold otherwise is to ignore a fundamental precept of the profession, that physicians must put the patient's interests above all others.

\section{Summary}

By limiting the hours that residents are allowed to work, the ACGME is attempting to reduce preventable harm to patients that occurs at the hands of sleepdeprived residents. This is a laudable goal. But in so doing, they have created a system that creates conflicts for residents who wish to practice ethically when doing so would violate the hour requirements. Rather than create a system that forces residents to sacrifice the ethics of the profession for patient safety, the ACGME should promulgate rules or effectuate changes that promote both.

\section{References}

1. ACGME. Statement of Justification/Impact for the Final Approval of Common Standards Related to Resident Duty Hours. September 2000.

2. Leach DC. Resident duty hours: the ACGME perspective. Neurology 2004;62:1E-2E. Available at: www.neurology.org 


\section{Neurology}

\section{Duty hours vs professional ethics: ACGME rules create conflicts \\ Dan Larriviere \\ Neurology 2004;63;E4-E5 \\ DOI 10.1212/WNL.63.1.E4}

\section{This information is current as of July 12, 2004}

\section{Updated Information \&} Services

Citations

Permissions \& Licensing

Reprints including high resolution figures, can be found at: http://n.neurology.org/content/63/1/E4.full

This article has been cited by 1 HighWire-hosted articles: http://n.neurology.org/content/63/1/E4.full\#\#otherarticles

Information about reproducing this article in parts (figures,tables) or in its entirety can be found online at:

http://www.neurology.org/about/about_the_journal\#permissions

Information about ordering reprints can be found online: http://n.neurology.org/subscribers/advertise

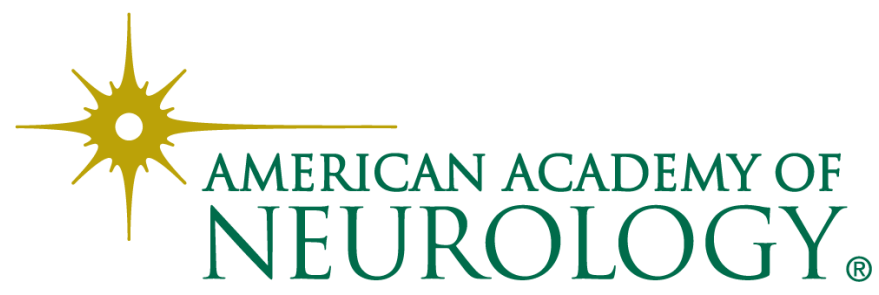

